" the cremasteric fascia, perhaps stronger than before, would probably remain, holding together the atrophied muscle bundles."

Inoculation of Syphilis upon an Anthropoid Ape.-With reference to the note in the September issue of this Journal, taken from a recent number of the Annales des Maladies des Organes Génito-Urinaires, it is of interest to add that the issue of the Gazette Médicale de Paris for 8th August, 1903, furnishes the following important information testifying to the scientific zeal and devotion of MM. Roux and Metchnikoff, of the Pasteur Institute.

The chimpanzee, which was inoculated by Professors Roux and Metchnikoff, being unfortunately an animal belonging to a class of considerable rarity, and efforts to inoculate other types of monkey having so far failed, the prosecution of the researches of these workers has become a difficult one, and promises to be attended by great expense.

The Pasteur Institute not being able to finance the work in obtaining chimpanzees and other monkeys necessary to the researches, MM. Roux and Metchnikoff have, by themselves, and with their own means, made up a substantial purse for their common use, by combining the 100,000 francs of the Osiris prize awarded by the Institute to Professor Roux with the 5,000 francs awarded to M. Metchnikoff. With these funds they propose carrying on their study, "trusting to find in the affection of the anthropoid ape the cure of the human disease."

In the words of the Gazette, "this action is a worthy one ; and when one is desirous of being successful, one ought not to hesitate in sacrificing even considerable sums of money, especially when from such undertakings may come so beneficent a result."

\title{
DISEASES OF THE EYE.
}

By FREELAND FERGUS, M.D.

A New Ophthalmic Magazine.-Since our last notes appeared in this Journal a new ophthalmic magazine, called T'he Ophthalmoscope, has been started in Great Britain. It is edited by ${ }^{*} \mathrm{Mr}$. Sydney Stephenson and subedited by Mr. Devereux Marshall, and is to appear monthly. The first two numbers promise well; especially we would call attention to the excellent paper by Mr. Adams Frost on "The Operative Treatment of High Myopia." It is hoped that this new publication will in no way be considered as antagonistic to the older Ophthalmic Review. There ought to be plenty of room for both in English-speaking countries. We notice that the new Journal has at once entered on the vexed question of spectacle vendors posing as ophthalmic experts. This is a question which admits of no discussion - the facts are plain enough-and we entirely espouse the views enunciated in the new magazine. At the same time, it will be a pity if such questions, however proper in themselves, bulk too largely in this new publication to the exclusion of the scientific ophthalmic work which is being done in Great Britain and in her colonies.

Chronic Infectious Sympathetic Ophthalmia.-This is an interesting paper in the Arch. d'Ophthal. by Abadie. Sympathetic ophthalmia has been regarded, ever since the days of $M$ 'Kenzie, as an acute or subacute disease; but here is another proof that it is not always so. If evidence goes on accumulating as it has done for some years back, it will soon be regarded as a wrong thing to leave in an eye under any circumstances which is injured beyond hope of good vision. It is not the acute or subacute sympathetic ophthalmia which alone has to be feared; there are also those slow processes of sympathetic degeneration which are very injurious to the sight of the injured eye. 
Surgical Treatment of the Lachrymal Passages.-Since Tartuferi published his valuable communication fully a year ago on the anatomy and pathology of the lachrymal passages, the methods of treating dacryocystitis chronica have been considerably altered. The standard methods of treatment, by passing probes and washing out the sac by means of a syringe, are only completely successful in a minority of cases. Any ophthalmic surgeon who carefully and accurately looks at the facts of the case will admit that these methods have been disappointing. The treatment by curetting, first advocated by Tartuferi, and more recently by Terson, seems, on the average, to give more satisfactory results.

An interesting report on the newer treatment will be found in the Archiv. d'Ophthalmologie. It is the joint production of Lapersonne and RochonDuvigneaud. We would also recommend to our readers' attention in the same journal a paper on "The Nature and Treatment of Prelachrymal Tumour." There was an indolent abscess in front of the sac, but the passages were perfectly free. It was probably connected with one of the subsidiary lachrymal passages described by Tartuferi. This anatomist's observations have cleared up many obscure points in the pathology of suppurative diseases of these passages.

Periscopic Lenses.-In Knapp's Archives of Ophthalmology Mr. Percival has an interesting short communication on this important subject, and supplies the necessary tables to enable ophthalmic surgeons to order such glasses. He says :- "Spectacles ordered according to this table will be accurately perioscopic for all eccentric vision within a solid angle of $50^{\circ}$ between the powers of $+8 \mathrm{I}$ and - 14 D." Anything Mr. Percival says is no doubt authoritative, and the tables cannot fail to be of service.

\title{
PUBLIC HEALTH AND INFECTIOUS DISEASE.
}

\author{
By HUGH GaLT, M.B., C.M. Glasg., D.P.Н. Самв.
}

Infant Life Protection.-In the Medical Magazine for August there is an interesting paper on the above subject by F. Zinnetti, Inspector to the Chorlton Union, Manchester. The author begins by referring to the recent debate in the House of Lords on national and physical degeneration, and quotes the statement of the Bishop of Ripon that at the present time there is a "shortage" of children to the extent of $1,500,000$, this being attributed by the Bishop to the decreasing birth-rate.

The problem of infant life protection is a very serious one, and the author is to be congratulated in again drawing attention prominently to the subject. He points out that, in his district, not only is the birth-rate decreasing, but the infantile death-rate has markedly increased within the last ten years. As the author says, it is a national duty to protect the lives of children, legitimate or illegitimate. Aids to this, as indicated in the paper, are the teaching of practical hygiene to the elder girls in school, and instruction in the care and management of children. The employment of married women in factories is also to be discouraged. The enormously greater death-rate amongst illegitimate children is emphasised, and the need for greater State protection in these cases.

The passing of the Infant Life Protection Act has been a step in the right direction, but it is pointed out that, like many other Acts, while the provisions are excellent, the carrying of them out on a large scale is beset with difficulties. The proposed amending Bill by the Poor Law Unions' Association in 1901 is shown by the author to go much further than the parent Bill, but, unfortunately, it did not reach a second reading. One of the chief defects in the present Act is that it does not provide for "single" cases, which are thus exposed to practically the same dangers as those existing before the passing of the Act. 